\title{
Body composition, water turnover and energy turnover assessment with labelled water
}

\author{
Klaas R. Westerterp \\ Department of Human Biology, Maastricht University, PO Box 616, 6200 MD Maastricht, The Netherlands
}

\begin{abstract}
Our understanding of human energy metabolism has benefited greatly from the application of water labelled with ${ }^{2} \mathrm{H}$ and ${ }^{18} \mathrm{O}$ for the measurement of total body water, water turnover and total daily energy expenditure. Applications include validation of techniques for the assessment of dietary intake and physical activity, assessment of water and energy requirement and the assessment of the effect of dietary and physical activity interventions, including its use with endurance athletes competing at the highest level. Critical aspects of the application are isotope dose preparation, sample collection, sample analysis and the calculation procedure. The labelledwater method can easily be applied in normal living conditions, including exercise, and in the clinical setting. However, sample analysis requires a sophisticated laboratory with an isotope-ratio mass spectrometer and a sample preparation system. Examples of insights based on labelled-water studies are: (1) self-reported dietary intakes often underestimate energy requirements; (2) subjects have problems maintaining energy balance when daily energy expenditure exceeds 2.5 times resting energy expenditure. Devices for the assessment of physical activity validated using labelled water allow the study of activity patterns and strategies to influence the activity level of a sedentary society.
\end{abstract}

Energy intake: Energy requirement: Energy balance: Exercise: Doubly-labelled water

Water labelled with ${ }^{2} \mathrm{H}$ is used for the measurement of total body water (TBW) and water turnover. Subjects are given a weighed dose of ${ }^{2} \mathrm{H}_{2} \mathrm{O}$ and the enrichment of the body water is measured after equilibration. Body composition (fat-free mass and fat mass) can be calculated from body mass and TBW with an assumption as to the hydration of the fat-free mass. Water turnover is calculated from the ${ }^{2} \mathrm{H}$-elimination rate after equilibration. Water labelled with ${ }^{2} \mathrm{H}$ and ${ }^{18} \mathrm{O}$ $\left({ }^{2} \mathrm{H}_{2}{ }^{18} \mathrm{O}\right)$ is used for the measurement of total daily energy expenditure (EE). Subjects are given a weighed dose of ${ }^{2} \mathrm{H}_{2}{ }^{18} \mathrm{O}$ which equilibrates with the body water. Subsequently, ${ }^{2} \mathrm{H}$ is eliminated as ${ }^{2} \mathrm{H}_{2} \mathrm{O}$ while ${ }^{18} \mathrm{O}$ is eliminated as both $\mathrm{H}_{2}{ }^{18} \mathrm{O}$ and $\mathrm{C}^{18} \mathrm{O}_{2}$. The difference between the two elimination rates is therefore a measure of $\mathrm{CO}_{2}$ production. $\mathrm{CO}_{2}$ production is converted to $\mathrm{EE}$ using an energy equivalent based on the substrate mixture oxidized.

The use of doubly-labelled water for the assessment of free-living $\mathrm{EE}$ in human subjects was first reported by Schoeller \& van Santen (1982), and the technique has subsequently been evaluated (Prentice, 1990; Speakman \& Roberts, 1995; Schoeller \& Delany, 1998). An example of what we have learnt by using the technique is the level of total $\mathrm{EE}$ in all age-groups, including premature infants, children, obese subjects, hospitalized patients, pregnant and lactating women, and the elderly. Currently, assessment of energy requirements is ideally based on measurements of $\mathrm{EE}$, as measured using doubly-labelled water. The activity level of a subject can be calculated by measurement of total $\mathrm{EE}$ in combination with $\mathrm{BMR}$, defined as the physical activity index (total EE/BMR). Human endurance athletes reach a maximum physical activity index of approximately 5, similar to that of wild animals (Hammond \& Diamond, 1997).

Application of labelled water for the assessment of body composition, water turnover and energy turnover involves preparation of the isotope dose, sample collection, sample analysis and calculation procedures. In addition, the protocol has to be designed to address the aim of the study in combination with the characteristics of the subject population. Doubly-labelled water for the measurement of total EE has now been applied in human subjects for about 15 years. Applications described later include validation of

\footnotetext{
Abbreviations: EE, energy expenditure; TBW, total body water; $\mathrm{TBW}_{\mathrm{uww}}$, total body water measured by underwater weighing. Corresponding author: Dr K. Westerterp, fax +31 43 3670976, email k.westerterp@ hb.unimaas.NL
} 
techniques for the assessment of dietary intake and physical activity, assessment of energy requirement, and the assessment of the effect of dietary and physical activity interventions, including its use with endurance athletes competing at the highest level.

\section{Isotope dose preparation, sample collection and sample analysis}

Stock mixtures are prepared from separate samples of (un)labelled water and individual doses measured by weight. A dilution of the stock mixture is prepared for mass spectrometric analysis. Stock mixtures, doses, and body fluid samples are stored in airtight screw-capped glass containers. We have observed that plastic containers are permeable to water and thus exchange of isotopes. This process results in changes in the isotope ratio of the contents of a closed plastic container, especially when the containers are not completely filled (Westerterp et al. 1995b). An additional advantage of glass containers is that samples do not have to be frozen during transport.

\section{Isotope dose}

${ }^{2} \mathrm{H}$ is obtained as a solution containing 99.9 atom \% (various suppliers) and ${ }^{18} \mathrm{O}$ as an aqueous solution containing 10 atom \% (four suppliers: Cambridge Isotope Labs, Andover, MA, USA; Isonics, Golden, $\mathrm{CO}$ and Miamisburg, $\mathrm{OH}$, USA; Rotem, Beer Sheva, Israel). Stock mixtures of 5-10 atom $\%$ are prepared using tap water, ideally for a complete group of subjects at one time. Doses are weighed out individually according to the expected dilution volume (TBW) of the subject. A duplicate sample of the stock mixture is retained for mass spectrometric analysis (for details of required sample size, see p. 946).

\section{Sample collection}

The sampling media for measuring the enrichment in the body fluid compartment are urine, saliva or blood. For urine sampling, urine from individual subjects is collected in a dry container and duplicate samples are taken. For each collection, urine can be kept in an airtight plastic container for up to $24 \mathrm{~h}$ before sampling and transfer to glass containers. For saliva sampling, subjects keep pre-dried dental cotton rolls under the tongue, then the cotton rolls are squeezed into a syringe to collect a duplicate sample. Subjects refrain from eating and drinking for $1 \mathrm{~h}$ before saliva sampling. For blood sampling, a water-free antiseptic is used to clean the skin, and a vacutainer with or without a dry anticoagulant is applied. Duplicate samples of serum are prepared by centrifugation of the blood sample. Sample containers should be stored at $-20^{\circ}$, although this temperature is not essential during transport of samples to the laboratory.

\section{Sample analysis}

After preparation samples are analysed using an isotoperatio mass spectrometer. Successful analysis requires a laboratory with an isotope-ratio mass spectrometer for ${ }^{2} \mathrm{H}$ and ${ }^{18} \mathrm{O}$, and experience with the analysis of the two isotopes in tracer amounts. Approximately 1 year is required to gain the necessary experience. An alternative is collaboration with one of the laboratories with the necessary research facilities or the analysis can be done in a commercial facility (Speakman, 1997). The sample size required for a duplicate ${ }^{2} \mathrm{H}$ and ${ }^{18} \mathrm{O}$ analysis is between 1 and $5 \mathrm{ml}$, depending on the sample preparation system used. The minimum sample size is that required for on-line sample preparation and the maximum sample size is that used when off-line equilibration techniques are involved. Presently, gas samples for the isotope-ratio mass spectrometer are often prepared by equilibration of the liquid sample with a gas. The usual gas for analysis of ${ }^{18} \mathrm{O}$ is $\mathrm{CO}_{2}$ and that for ${ }^{2} \mathrm{H}$ is $\mathrm{H}_{2} . \mathrm{CO}_{2}$ is added to the water sample and exchanges unlabelled $\mathrm{O}$ for ${ }^{18} \mathrm{O}$ from the water (Wong et al. 1987). $\mathrm{H}_{2}$ is added to the water sample and exchanges unlabelled $\mathrm{H}$ for ${ }^{2} \mathrm{H}$ from the water, with $\mathrm{Pt}$ as a catalyst (Scrimgeour et al. 1993). In future, sample preparation techniques for sample sizes of the order of microlitres will involve continuous-flow-pyrolysis isotope-ratio mass spectrometry (Begley \& Scrimgeour, 1997).

\section{Protocols}

\section{Measurement of body composition}

Body water is usually measured using ${ }^{2} \mathrm{H}$ dilution, which is 100 times cheaper than ${ }^{18} \mathrm{O}$ at the present prices. The dose is calculated to reach an excess enrichment of about $10010^{-4}$ atom $\%$, based on estimated body water from age- and sexspecific formulas (Westerterp et al. 1995a). Before administration of the isotope dose, a background sample is collected from each subject. For oral administration, subjects drink the water directly from the bottle. The bottle is rinsed with $50-75 \mathrm{ml}$ tap water which is also consumed. For intragastric and intravenous administration, the dose container is reweighed after dose administration and the infusion tubes are flushed with the infusion fluid.

In the preferred protocol, a subject consumes the dose at night before bedtime, the equilibration takes place overnight and a second collection of urine, saliva or blood is made the following morning before breakfast, resulting in a 10 h equilibration time (van Marken Lichtenbelt et al. 1994, 1996). Alternatively, a subject is given the dose after an overnight fast and consumes no food or drink until the final sample from the second collection of urine, saliva or blood after $4 \mathrm{~h}$.

\section{Measurement of water turnover}

Subjects are given a weighed dose of ${ }^{2} \mathrm{H}_{2} \mathrm{O}$ resulting in an initial excess of 70-150 $10^{-4}$ atom $\%{ }^{2} \mathrm{H}$, depending on the estimated biological half-life of the label and the planned observation interval. The optimal observation interval is one to three biological half-lives of the isotope (Lifson \& McClintock, 1966), i.e. from $3 \mathrm{~d}$ at the upper limit of endurance exercise to $40 \mathrm{~d}$ in extremely sedentary subjects with a low water intake (Fig. 1(a)). 

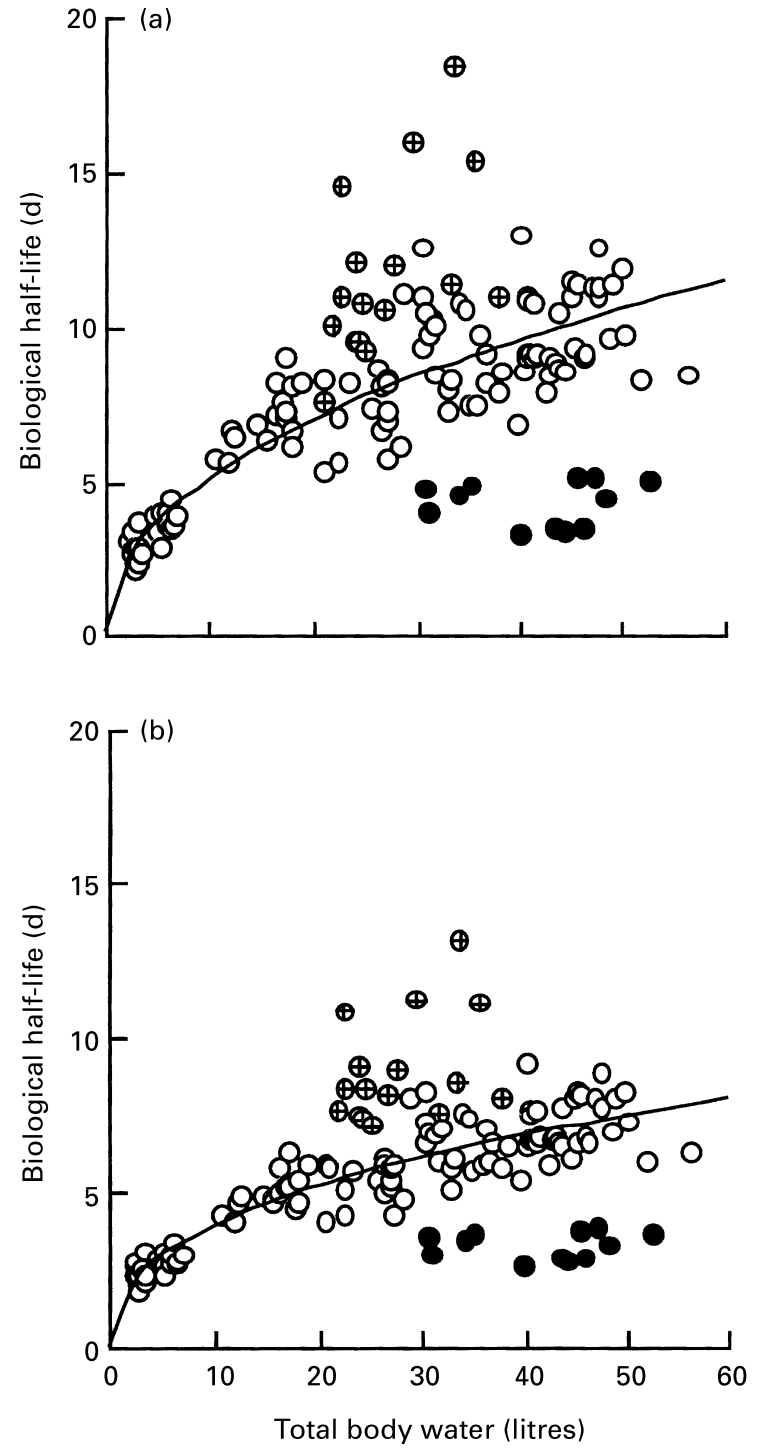

Fig. 1. Biological half-lives of (a) ${ }^{2} \mathrm{H}$ and (b) ${ }^{18} \mathrm{O}$ as a function of total body water in institutionalized elderly subjects $(\oplus)$, normally active subjects $(O)$ and elite endurance athletes $(\bullet)$. (Data from Westerterp et al. 1986, 1996; van den Berg-Emons et al. 1995; de Bruim et al. 1998; WG van Gemert, unpublished results; M Persson, unpublished results.)

In a routine protocol for children, adolescents and adults, we give $70 \mathrm{ml}$ of a solution in tap water $(50 \mathrm{ml} / \mathrm{l})$ for oral administration, and measure total water loss over the subsequent 1-week interval. The dose is administered at night (day 0 ) after collection of a background urine sample, as for the measurement of body composition. Further urine samples are two collections, on days 1 and 8.

\section{Measurement of energy expenditure}

The isotopes are administered as a mixture of ${ }^{2} \mathrm{H}_{2} \mathrm{O}$ and $\mathrm{H}_{2}{ }^{18} \mathrm{O}$ resulting in an initial excess body-water enrichment of $15010^{-4}$ atom $\%$ for ${ }^{2} \mathrm{H}$ and $30010^{-4}$ atom $\%$ for ${ }^{18} \mathrm{O}$, leaving a sufficient excess enrichment at the end of the observation period (Schoeller, 1983). The volume is $80-160 \mathrm{ml}$ for adults. In the preferred protocol the isotopes are administered as the last intake of the evening after background sampling (see measurement of body composition, p. 946). Equilibration then takes place overnight and the first enriched sample is collected in the early morning, in the case of urine from the second collection. The optimal observation interval following the first sample is one to three biological half-lives of the isotopes (Lifson \& McClintock, 1966), i.e. from $2.5 \mathrm{~d}$ in extremely active subjects to $30 \mathrm{~d}$ in the sedentary elderly (Fig. 1(b)). For an observation period of 1 week or shorter, subsequent urine samples are taken from the second collection each day. For an observation period of more than 1 week, samples from the second and further collections on the first, middle and last day of the observation period are sufficient.

There are three criteria to judge the validity of the results of isotope analyses for EE measurements. First, duplicate analyses should not differ by more than $110^{-4}$ atom $\%$. Typically the standard deviation for replicate samples averages $0 \cdot 210^{-4}$ atom $\%$ and $0 \cdot 310^{-4}$ atom $\%$ for ${ }^{2} \mathrm{H}$ and ${ }^{18} \mathrm{O}$ respectively (Forsum et al. 1992). Second, the value for ${ }^{2} \mathrm{H}$ dilution space $:{ }^{18} \mathrm{O}$ dilution space is expected to be close to 1.03 (Speakman, 1997). As a third criterion, the fit of the isotope-elimination curves should be high, or results based on morning and evening samples over corresponding intervals should be close (Westerterp et al. 1995b). The protocol allows comparisons of calculated EE within the first and second week of a $14 \mathrm{~d}$ observation period in order to check for sampling errors. Typically, the difference is smaller than $10 \%$ and samples are re-analysed when the difference is larger (Westerterp et al. 1995b). The calculation of EE from isotope decay involves assumptions as to the isotope dilution spaces for ${ }^{2} \mathrm{H}$ and ${ }^{18} \mathrm{O}$. The advice is to use a fixed ratio based on the population mean of a study group.

\section{Calculation procedures}

The calculation of TBW is based on the relationship:

$$
\mathrm{C}_{1} \mathrm{~V}_{1}=\mathrm{C}_{2} \mathrm{~V}_{2} \text {, }
$$

where $C_{1}$ and $V_{1}$ are the concentration of the tracer and the volume of the dose respectively, $\mathrm{C}_{2}$ is the concentration of the tracer in the body water, and $\mathrm{V}_{2}$ is the dilution space of the isotope in the body. The dilution space for ${ }^{2} \mathrm{H}(\mathrm{Dh})$ is on average $4 \%$ larger than TBW and the dilution space for ${ }^{18} \mathrm{O}$ (Do) is on average $1 \%$ larger than TBW, due to the exchange of the label with non-aqueous substances in the body:

$$
\begin{gathered}
\mathrm{TBW}=\mathrm{Dh} / 1 \cdot 04, \\
\text { Do } / 1 \cdot 01 .
\end{gathered}
$$

The calculation of water turnover $\left(\mathrm{rH}_{2} \mathrm{O}\right)$ is based on the relationship:

$$
\mathrm{rH}_{2} \mathrm{O}=(k h \times \mathrm{Dh}) / f
$$


where $k h$ and $\mathrm{Dh}$ are the elimination rate and dilution space for ${ }^{2} \mathrm{H}$ respectively, and $f$ is the fractionation correction for ${ }^{2} \mathrm{H}$ leaving the body via breath water and insensible cutaneous water. The fractionation correction is calculated according to Schoeller et al. (1986), based on assumptions of the proportion of total water loss via fractionated routes.

The calculation of $\mathrm{EE}$ from the rate of $\mathrm{CO}_{2}$ production $\left(\mathrm{rCO}_{2}\right)$ is based on the relationship:

$$
\mathrm{rCO}_{2}=\frac{k o \times \mathrm{Do}-k h \times \mathrm{Dh}}{2 \times f 3}-\frac{f 2-f 1}{2 \times f 3} \times \mathrm{rGf}
$$

where $k o$, Do, $k h$ and Dh are elimination rates and dilution spaces for ${ }^{18} \mathrm{O}$ and ${ }^{2} \mathrm{H}$ respectively, factors $f 1, f 2$ and $f 3$ are for fractionation of ${ }^{2} \mathrm{H}$ in water vapour $(0.941),{ }^{18} \mathrm{O}$ in water vapour (0.992) and ${ }^{18} \mathrm{O}$ in $\mathrm{CO}_{2}(1.039)$ respectively and $\mathrm{rGf}$ is the rate of isotopically-fractionated gaseous water loss. Then:

$$
\mathrm{rGf}=1.8 \times 1.77 \times \mathrm{rCO}_{2},
$$

assuming that breath is saturated with water and contains 3.5 $\% \mathrm{CO}_{2}$ (fractionated breath water $=1.77 \times \mathrm{rCO}_{2}$ ) and transcutaneous fractionated (non-sweat) water loss amounts to approximately $30 \%$ of the breath water $(80 \%$ of the breath water in babies). Then:

$\mathrm{rCO}_{2}=0.455 \mathrm{~N} \times(1.01 \times k o-1.04 \times k h)$,

and for babies: $\mathrm{rCO}_{2}=0.445 \mathrm{~N} \times(1.01 \times k o-1.04 \times k h)$,

where $\mathrm{N}$ is the TBW calculated from the isotope dilution spaces $((\mathrm{Do} / 1.01+\mathrm{Dh} / 1.04) / 2)$ at the start of the observation period, corrected for the change over the observation period. The latter correction is calculated from the difference between initial and final body weight of the subjects during the study, assuming the change of the body water volume is linear and proportional to the change in weight.

$\mathrm{CO}_{2}$ production is converted to $\mathrm{EE}$ using an energy equivalent based on the substrate mixture oxidized.

\section{Important issues}

\section{Background isotope levels}

Before administration of the isotope dose, a background sample is collected from each subject. Background levels differ between subjects and over time (season). We measured ${ }^{2} \mathrm{H}$ and ${ }^{18} \mathrm{O}$ values ranging from 138 (SD 0.2) to 155.6 (SD 0.4) $10^{-4}$ atom $\%$ for ${ }^{2} \mathrm{H}$ and from 1979.7 (SD 0.4) to 2006.7 (SD 1.0 ) $10^{-4}$ atom $\%$ for ${ }^{18} \mathrm{O}$ in subjects climbing Mount Everest and in subjects during offshore sailing races respectively (Westerterp et al. 1995b).

\section{Body composition}

For obvious reasons, there is no direct method to measure TBW in man. The 'gold standard' for measurements of body composition in human subjects is underwater weighing. With the assumption of a two-compartment model (fat mass and fat-free mass, the latter containing all the body water, which comprises $730 \mathrm{~g} / \mathrm{kg}$ fat-free mass), it is possible to compare this indirect measure for $\mathrm{TBW}\left(\mathrm{TBW}_{\mathrm{uww}}\right)$ with data from isotope dilution. In a comparative study, TBW was measured in twenty-nine subjects, once using underwater weighing and three times using ${ }^{2} \mathrm{H}$ dilution with different protocols (van Marken Lichtenbelt et al. 1994), i.e. (1) dose after an overnight fast and no food or drink until the final sample from second urine collection made after $4 \mathrm{~h}$, (2) dose after an overnight fast and no food or drink restrictions until final sample from second collection made after $4 \mathrm{~h}$, (3) dose at night before bedtime and final sample from second collection made the following morning, resulting in an equilibration interval of approximately $10 \mathrm{~h}$.

The comparison of $\mathrm{TBW}_{\mathrm{uww}}$ with $\mathrm{TBW}$ from ${ }^{2} \mathrm{H}$ dilution using linear regression resulted in 0.97-0.99 with all three protocols. Protocols 1 and 2 resulted in a mean underestimate of TBW from ${ }^{2} \mathrm{H}$ dilution of 5.6 (SE 0.5) \% $(P<0.001)$ and $4.1(\mathrm{SD} 0.6) \%(P<0.001)$ respectively. The difference between TBW from ${ }^{2} \mathrm{H}$ dilution measured after $4 \mathrm{~h}$ and $\mathrm{TBW}_{\mathrm{uww}}$ was significantly related to the average of both measurements. However, results using protocol 3 were not related to $\mathrm{TBW}_{\mathrm{uww}}$ (mean difference $-1 \cdot 1$ (SE 0.7) \%). Comparing a larger data set, one group with the $4 \mathrm{~h}$ protocol ( $n$ 60) and another group with the $10 \mathrm{~h}$ protocol $(n 70)$, underlined the differences between the $4 \mathrm{~h}$ and $10 \mathrm{~h}$ equilibration times (Westerterp et al. 1995b). When measuring body water, many laboratories use a $4 \mathrm{~h}$ protocol, measuring isotope enrichment in blood, saliva or urine. The present study shows a systematic difference between $\mathrm{TBW}_{\mathrm{uww}}$ and TBW measured using isotope dilution after $4 \mathrm{~h}$. Moreover, the difference was related to the size of the body-water volume. It can be argued that it takes longer for the isotopes to equilibrate with urine, even when a second collection made at $4 \mathrm{~h}$ after dosing is sampled. However, this factor would not explain why the discrepancy when composed with $\mathrm{TBW}_{\text {uww }}$ is larger in subjects with a larger body-water volume. No such discrepancy and no significant differences between TBW from ${ }^{2} \mathrm{H}$ and $\mathrm{TBW}_{\mathrm{uww}}$ were found after $10 \mathrm{~h}$ (overnight) equilibration. Although some of the ${ }^{2} \mathrm{H}$ is already washed out during equilibration, a $10 \mathrm{~h}$ sampling protocol seems to be preferable for determining TBW, because of greater consistency in the results. Schoeller \& van Santen (1982) used a protocol in which TBW was measured in saliva after $4 \mathrm{~h}$ and subsequent measurements for the determination of EE were made in urine, starting after $24 \mathrm{~h}$. The $10 \mathrm{~h}$ protocol is probably a good compromise, combining both measurements in one sampling medium (urine).

\section{Energy expenditure}

The ultimate check on the validity of measurement of body composition and EE with labelled water in the field is the measurement of energy balance, i.e. energy intake, EE and changes in energy reserves of the body. Using the protocol described, Velthuis-te Wierik et al. (1995) measured EE and changes in the energy reserves of the body over $14 \mathrm{~d}$ in eight subjects receiving a weight-maintenance diet based on a $7 \mathrm{~d}$ dietary record. Six of the eight subjects lost weight. The mean discrepancy between energy intake and EE over the 
$14 \mathrm{~d}$ interval was -34.5 (SE 11.2) MJ. The mean changes in body weight and TBW over the corresponding interval were respectively 1.13 (SE 0.46) kg and -0.25 (SE 0.32) litres. There was a highly significant relationship between the body mass change $(\Delta \mathrm{BM} ; \mathrm{kg})$ and the energy balance (energy intake-EE; MJ): $\Delta \mathrm{BM}=0.034$ (energy intake-EE) $+0.06(r 0.84, P<0.01)$. The energy equivalent of the body mass change calculated from the change in weight and body water was 0.25 litres water, equivalent to $0.34 \mathrm{~kg}$ fat-free mass containing $730 \mathrm{~g}$ water $/ \mathrm{kg}$ or $0.34 \times 4=1.4 \mathrm{MJ}$, and the remaining weight loss of $1.13-0.34=0.79 \mathrm{~kg}$ being fat or $0.79 \times 37=29.2 \mathrm{MJ}$, together $30.6 \mathrm{MJ}$ for $1.13 \mathrm{~kg}$ or $27 \mathrm{MJ} / \mathrm{kg}$. This value is very close to the $28 \mathrm{MJ} / \mathrm{kg}$ calculated from the relationship between the body mass change and the energy balance. The energy balance study also shows the (normal) under-reporting of energy intake as measured using a dietary record. Energy intake minus $\mathrm{EE}$ and expressed as a percentage of EE was -16.0 (SE 4.5) \%. Feeding subjects according to their reported intake resulted in weight loss. The energy equivalent of the weight loss corresponded to the energy deficit.

\section{Applications}

\section{Validation of techniques for the assessment of dietary intake}

Since the application of doubly-labelled water for the measurement of EE we know that self-reported energy intake is an underestimate of energy requirements. An early example of the discrepancies between recorded energy intake and measured EE was provided in a study of energy metabolism in the Tour de France cycle race (Westerterp et al. 1986). Four participants recorded their daily food consumption during the $22 \mathrm{~d}$ race in specially designed diaries. A trained nutritionist gave instructions on filling in the diaries, made weekly checks and cross-checked with information about the food supply during the race, including energy-rich beverages. EE was measured simultaneously over three subsequent $7 \mathrm{~d}$ intervals using doubly-labelled water. All four subjects managed to meet their EE with energy intake, in view of their unchanged body energy reserves. However, recorded energy intake was lower than measured EE (Fig. 2). The discrepancy showed a systematic increment from 17 (SD 5) \% in the first week to 27 (SD 6) in the second week and to 35 (SD 2) \% in the third week. Subjects probably cannot and will not accurately recall what they have eaten at the end of the day or whenever intake is recorded in the diary. In addition, there appears to be a time effect; the longer the observation continues, the larger the discrepancy between recorded energy intake and measured $\mathrm{EE}$, i.e. the larger the under-reporting of energy intake. A comparable effect was measured in subjects preparing to run a half-marathon competition after 44 weeks (Westerterp et al. 1992). Measurement of energy intake using a $7 \mathrm{~d}$ dietary record was performed before (week 0 ), and 8,20 , and 40 weeks after the start of the training. At week 0 the difference between energy intake and simultaneously measured EE using doubly-labelled water was -4 (SD 16) \%. However, at week 40 reported energy intake was unchanged while EE was increased by 21 (SD 10)

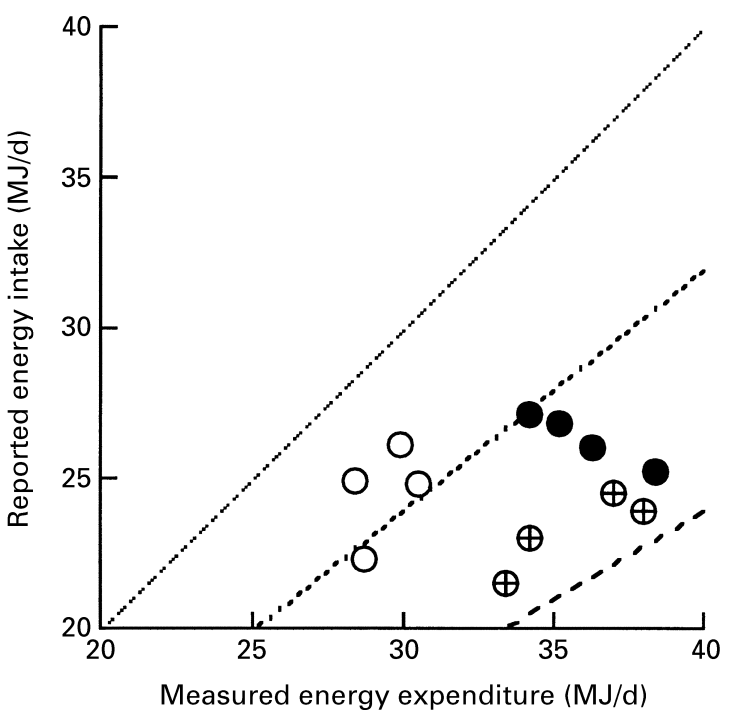

Fig. 2. Reported dietary energy intake (week 0) and measured energy expenditure in weeks $1(\bigcirc), 2(\bullet)$ and $3(\oplus)$ of four participants in the Tour de France cycle race. (---), $0 \%$ Underreporting; ( $\cdots$ ), $20 \%$ under-reporting; (- - -), $40 \%$ under-reporting. (Adapted from Westerterp et al. 1986.)

$\%$, and thus subjects significantly under-reported energy intake. The difference between energy intake and measured $\mathrm{EE}$ at week 40 was at -19 (SD 17) \% nearly equivalent to the increase in energy requirements. Here, the increase in underreporting with time occurred together with an increase in $\mathrm{EE}$, and subjects might not have been aware of the increase in intake, still recording unchanged portion sizes while actual portion sizes increased, or subjects forgot to record any extra snacks.

\section{Validation of techniques for the assessment of physical activity}

Doubly-labelled water is a 'gold standard' for the validation of techniques for the assessment of physical activity such as behavioural observation, questionnaires (including diaries, recall questionnaires and interviews), physiological markers such as heart rate, and motion sensors. The most promising are motion sensors, specifically accelerometers, as an objective tool for the assessment of physical activity in large populations and over intervals of days to periods long enough to be representative of normal daily life and with minimal discomfort to the subjects. Accelerometers developed in our laboratory consisted initially of a triaxial sensor, weighing about $25 \mathrm{~g}$, connected to a small data acquisition unit, $110 \times 70 \times 35 \mathrm{~mm}$, weighing $250 \mathrm{~g}$ (Bouten et al. 1996). Activity counts over $1 \mathrm{~min}$ intervals are stored for up to 3 weeks and can be downloaded. Recently, sensor and data acquisition were combined into one system, $70 \times 20 \times 8 \mathrm{~mm}$, weighing $30 \mathrm{~g}$ (Philips Research, Eindhoven, The Netherlands). Accelerometer output explained most of the variation in EE assessed by doublylabelled water, after adjustment for resting $\mathrm{EE}\left(R^{2}=0 \cdot 64\right.$, SE of estimate 0.9 MJ/d; Westerterp \& Bouten, 1997). 


\section{Assessment of energy requirement}

Since the application of doubly-labelled water, energy requirements are assessed preferably by measuring EE. Thus, we know the limits of energy turnover in relation to physical performance for the achievement of energy balance (Westerterp, 1998). At a population level, daily $\mathrm{EE}$ as a multiple of resting $\mathrm{EE}$ (EE/resting $\mathrm{EE}$ ) ranges from 1.2 to 2.5 (Black et al. 1996). At EE/resting EE values of approximately $2 \cdot 5$, subjects begin to have problems in maintaining energy balance. Five studies on soldiers during field training, together comprising sixty-six subjects with a mean EE/resting EE value of 2.40 (SE 0.46), all reported a negative energy balance over the observation period. The body-weight loss ranged from 0.4 to $2.3 \mathrm{~kg} /$ week

Examples where energy balance is maintained at EE/resting EE values greater than 2.5 are shown in studies on endurance athletes such as runners, cross-country skiers and professional cyclists. The reasons for the difference from the studies on soldiers are probably two-fold. First, professional endurance athletes are a selection of the population trained over many years to reach a high level of performance. Second, endurance athletes manage to maintain energy balance at a high level of energy turnover by supplementing the diet with energy-dense carbohydraterich liquid formulas.

\section{Assessment of the effect of physical activity interventions including endurance exercise}

There is a limited number of exercise intervention studies measuring the effect on daily EE (Westerterp, 1998). Two studies measured the effect of jogging as a means of increasing physical activity and three included indoor exercises, stationary cycling on a cycle ergometer and weight-training. Exercise training does not influence spontaneous activity (except in the elderly). In sedentary subjects, exercise training does not influence resting metabolic rate when body weight is maintained. An exercise-induced increase in average daily metabolic rate is about twice the training load.

\section{References}

Begley IS \& Scrimgeour CM (1997) High-precision $\delta^{2} \mathrm{H}$ and $\delta^{18} \mathrm{O}$ measurement for water and volatile organic compounds by continuous-flow pyrolysis isotope ratio mass spectrometry. Analytical Chemistry 69, 1530-1535.

Black AE, Coward WA, Cole TJ \& Prentice AM (1996) Human energy expenditure in affluent societies: an analysis of 574 doubly-labelled water measurements. European Journal of Clinical Nutrition 50, 72-92.

Bouten CVC, Verboeket-van de Venne WPHG, Westerterp KR, Verduin M \& Janssen JD (1996) Physical activity assessment: comparison between movement registration and doubly labeled water. Journal of Applied Physiology 81, 1019-1026.

de Bruin NC, Degenhart HJ, Gàl S, Westerterp KR, Stijnen T \& Visser HKA (1998) Energy utilization and growth in breast-fed and formula-fed infants, measured prospectively during the first year of life. American Journal of Clinical Nutrition 67, 885-896.

Forsum E, Kabir N, Sadurskis A \& Westerterp KR (1992) Total energy expenditure of healthy Swedish women during pregnancy and lactation. American Journal of Clinical Nutrition 56, 334-342.

Hammond KA \& Diamond J (1997) Maximal sustained energy budgets in humans and animals. Nature 386, 457-462.

Lifson N \& McClintock R (1966) Theory of use of turnover rates of body water for measuring energy and material balance. Journal of Theoretical Biology 12, 46-74.

Prentice AM (1990) The Doubly-labelled Water Method For Measuring Energy Expenditure, Technical Recommendations For Use In Humans. Section Nutritional and Health Related Environmental Studies, Vienna: International Atomic Energy Agency.

Schoeller DA (1983) Energy expenditure from doubly labeled water: some fundamental considerations in humans. American Journal of Clinical Nutrition 38, 999-1005.

Schoeller DA \& DeLany JP (1998) Human energy balance: what have we learned from the doubly labeled water method? American Journal of Clinical Nutrition 68, Suppl., 927S-979S.

Schoeller DA, Leitch CA \& Brown C (1986) Doubly labeled water method: in vivo oxygen and hydrogen isotope fractionation. American Journal of Physiology 251, R1137-R1143.

Schoeller DA \& van Santen E (1982) Measurement of energy expenditure in humans by doubly-labeled water method. Journal of Applied Physiology 53, 955-959.

Speakman JR (1997) Doubly Labelled Water: Theory and Practice. London: Chapman \& Hall.

Speakman JR \& Roberts SB (1995) Recent advances in the doubly labeled water technique. Obesity Research 3, Suppl. 1, 1-74.

Scrimgeour CM, Rollo MM, Mudambo SMKT, Handley LL \& Prosser SJ (1993) A simplified method for deuterium/hydrogen isotope ratio measurements on water samples of biological origin. Biological Mass Spectrometry 22, 383-387.

van den Berg-Emons HJG, Saris WHM, de Barbanson DC, Westerterp KR, Huson A \& van Baak MA (1995) Daily physical activity of schoolchildren with spastic diplegia and healthy control subjects. Journal of Pediatrics 127, 578-584.

van Etten LMLA, Westerterp KR, Verstappen FTJ, Boon BJB \& Saris WHM (1997) Effect of an 18-wk weight-training program on energy expenditure and physical activity. Journal of Applied Physiology 82, 298-304.

van Marken Lichtenbelt WD, Kester A, Baarends EM \& Westerterp KR (1996) Bromide dilution in adults: optimal equilibration time after oral administration. Journal of Applied Physiology 81, $653-656$

van Marken Lichtenbelt WD, Westerterp KR \& Wouters L (1994) Deuterium dilution as a method to determine total body water: effect of test protocol and sampling time. British Journal of Nutrition 72, 491-497.

Velthuis-te Wierik EJM, Westerterp KR \& van den Berg H (1995) Impact of a moderately energy-restricted diet on energy metabolism and body composition in non-obese men. International Journal of Obesity 19, 318-324.

Westerterp KR (1998) Alterations in energy balance with exercise. American Journal of Clinical Nutrition 68, 970S-974S.

Westerterp KR \& Bouten CVC (1997) Physical activity assessment: comparison between movement registration and doubly labeled water method. Zeitschrift für Ernährungswissenschaften 36, 263-267.

Westerterp KR, Donkers J, Fredrix EWHM \& Boekhoudt P (1995a) Energy intake, physical activity and body weight; a simulation model. British Journal of Nutrition 73, 337-347.

Westerterp KR, Meijer GAL, Janssen EME, Saris WHM \& ten Hoor F (1992) Long term effect of physical activity on energy balance and body composition. British Journal of Nutrition $\mathbf{6 8}$, 21-30.

Westerterp KR, Saris WHM, Van Es M \& ten Hoor F (1986) Use of the doubly labeled water technique in man during 
heavy sustained exercise. Journal of Applied Physiology 61, 2162-2167.

Westerterp KR, Verboeket-van de Venne WPHG, Bouten CVC, de Graaf C, van het Hof KH \& Weststrate JA (1996) Energy expenditure and physical activity in subjects consuming full- or reduced-fat diets. British Journal of Nutrition 76, 785-795.
Westerterp KR, Wouters L \& van Marken Lichtenbelt WD (1995b) The Maastricht protocol for the measurement of body composition and energy expenditure with labeled water. Obesity Research 3, Suppl. 1, 49-57.

Wong WW, Lee LS \& Klein PD (1987) Deuterium and ${ }^{18}$ oxygen measurements on microlitre samples of urine, plasma, saliva and human milk. American Journal of Clinical Nutrition 45, 905-913. 